الفحوصات الدموية لمرضى التهاب الكبد المناعي الذاتي وعلاقتها بالتهاب الكبد الفيروسي نوع ل

$$
\begin{aligned}
& \text { محمد بن محمد علي ابيض } \\
& \text { محمود عبد الجبار حسين } \\
& \text { قسم علم الحياة الحيوانية/ كلية العلوم/ جامعة حلب / سوريا } \\
& \text { قسم علوم الحياة/ كلية العلوم/ جامعة الموصل }
\end{aligned}
$$

\begin{abstract}
الملخص
جُمعت 167 عينة دم من مرضى مصابين بالتهاب الكبد المناعي الذاتي من النمط الأول Type-1، من المراجعين

لعيادات مستثفى حلب الجامعي ومستشفى زاهي ازرق (مستشفى الحميات) في حلب، وذلك خلال الفترة بين 4-2008 و 4 42009 وذلك لغرض إجراء تحاليل دموية عليها باستخدام تقنيات حديثة، إذ تم تحديد سرعة ترسيب كريات الدم الحمراء، وتعداد كريات الدم البيضاء والصفيحات الدموية، إضافة إلى تحديد نركيز الخضاب بالدم، وكذلك زمن البروثرومبين، وتم تحديد الفروقات ذات المعنى بوساطة إجراء التحليل الإحصائي. وأظهرت النتائج نسبة 72,22\% و 28,57\% في التعداد الكلي لكريات الدم البيضاء و 84,1\% لخضاب الدم، وظهرت القيم غير الطبيعية لكل من تعداد الصفيحات الدموية وزمن البروثرومبين بنسبة 17,07 \% و 84,85 على التوالي. وأتنتت الدراسة الإحصائية وجود فروقات معنوية واضحة بين مرض التهاب الكبد المناعي الذاتي وتعداد كريات الدم البيضاء على مستوى اقل من

الكلمات الدالة: التهاب الكبد المناعي الذاتي، الفحوصات الدموية، التهاب الكبد الفيروسي C.
\end{abstract}

\title{
Hematological Tests for Patients of Autoimmune Hepatitis and its Relation with HCV Infection
}

\author{
Mahmood A . Husain \\ Department of Biology/ College of Science \\ University of Mosul
Mohamed A. Abide
Department of Animal Biology/ College of Sciencel
University of Aleppo \\ Mahmood M. Nasser \\ Department of Digestive/College of Sciencel University of Aleppo
}

\begin{abstract}
One hundered sixty seven blood samples from patients with autoimmune hepatitis type -1 were collected, and reviewers of the Aleppo University Hospital clinics and hospital Zahi Asrac (Fever Hospital) in Aleppo, during the period between 4-2008 and 4-2009 of conducting blood tests and by using New techniques, Erythrocyte sedimentation rate and-WBC counts were done $72.22 \%$, $28.57 \%$, $\mathrm{Hb}$ conc $84.1 \%$. and, platelet count, prothrombin time increased by $17.07 \%$ and $84.85 \%$ respectively. Statistical difference were determined using statistical analyses the results showed significance and clear distinction between autoimmune hepatitis and count of white blood cells at the level of less than 0,001 .
\end{abstract}

Keywords: Autoimmune hepatitis, Hematology test, HCV. 


\section{المقدمة}

تعاني آليات الجهاز المناعي من الخلل في الوظيفة لاسباب غير معروفة، مثال ذلك أمراض العوز المناعي Di George syndrome ومتلازمة دي جورج Agama globulinemia منل نقص غاما غلوبين Immunodeficiency's ومتلازمة ويسكوت الدرايخ Wiscott Aldrich Syndrome ونقص الغاماغلوبين المكتسب مجهول السبب)، وكذلك أمراض فرط الحساسية Hypersensitivity من النمط الأول أو ما يسمى بتفاعل التآخي Anaphylaxis أو النمط الثاني reaction أو فرط الحساسية المتأخر delayed hypersensitivity. وتعد أمراض المناعة الذاتية الأكثر أهميةً وانتشاراً وخطورة مأول

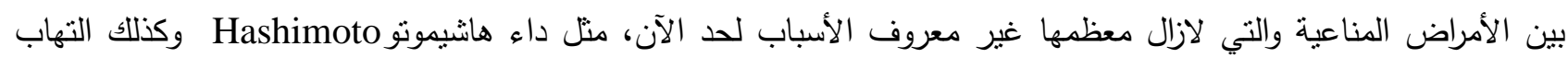
الكبد المناعي الذاتي (Autoimmune hepatitis (AIH)، وهناك في الولايات المتحدة الأمريكية لوحدها حوالي 20 مليون

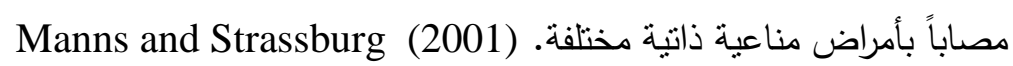

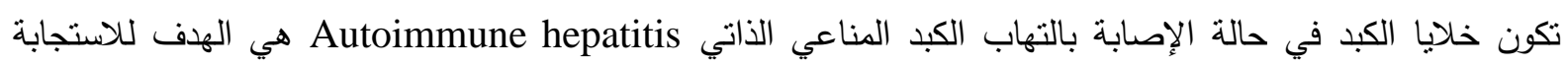

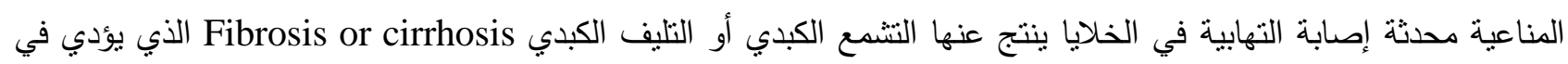
النهاية إلى الفنثل الكبدي. ويتم تشخيص هذا المرض بوساطة تشخيص وجود الأضداد الذاتية Autoantibodies مثل أضداد العضلات الملساء Anti smooth muscular antibodies ASMS وأضداد النواة Anti Nuclear Antibodies ANA وأضداد ميكروزوم الكبد والكلية Anti liver, kidney microsomal antibodies ALKM-1 وأضداد الكبد الذائب Atuble

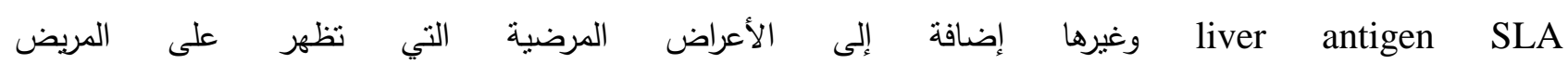
.Manns and Strassburg, (2001) إن سبب حدوث المرض غير معروف لحد الآن لكنه يعتقد أن مستضداً ذاتياً يظهر على سطح خلايا الكبد ولأسباب غير

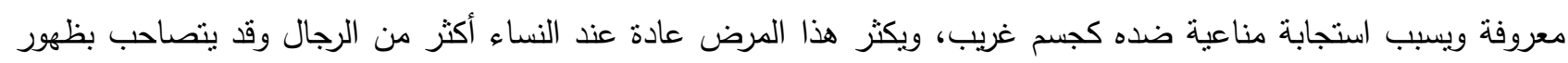

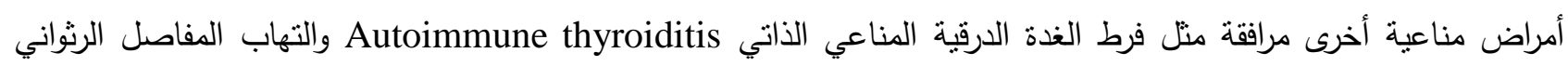
.Adam (2006) Rheumatoid arthritis وقد قام العالم Waldenstrem وزميله في عام 1950 لأول مرة بوصف متلازمة يتظاهر فيها الكبد بالتهاب مزمن، يحدث بشكل خاص عند اليافعين وخاصة النساء، وكان يدعى التهاب الكبد الوبائي، وقد وجد ان المرض يظهر بأنكال متعددة

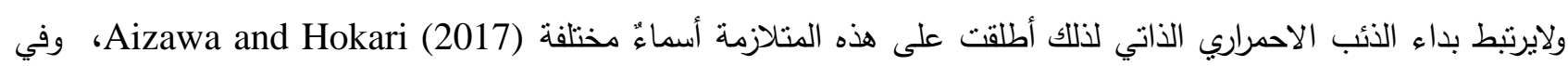

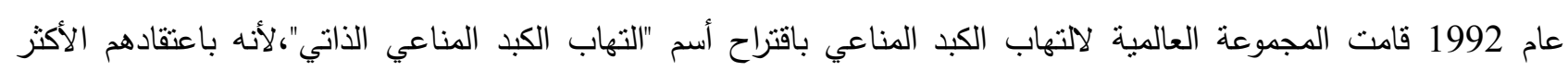
ملائمة لهذا المرض (2005) (2006); Desai (20) ويعرف التهاب الكبد المناعي الذاتي AIH and Herschel بأنه مرض مزمن غير معروف الأسباب وهو يحدث نتيجة للعملية الالتهابية inflammation التي تحدث داخل الكبد نتيجة لاستجابة مناعية ذاتية ضد خلايا الكبد نفسها، وفي الحالات المتقدمة من المرض وبغياب العلاج المناسب تؤدي هذه الحالة الالتهابية إلى تلف خلايا الكبد مما يؤدي إلى مشكلة خطيرة تنتهي بنليف الكبد التي لربما ادت الى الوفاة، ولها عدة أسباب منها تعاطي الكحول

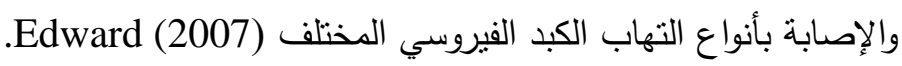
إن أسباب حدوث المرض غبر واضحة كما ذكر آنفا، وقد يأتي من خلال استجابة مناعية ذاتية ضد إصابات بكتبرية أو جرثومية أو فيروسية أو أي جسم غريب آخر • وتزداد هذه الحالة عند الأشخاص الذين يعانون من أمراض مناعية ذاتية أخرى مثل من فئل الإصابة بداء الذأب الحمامي المجموعي SLE ومتلازمة جوغرن أو فرط الغدة الدرقية أو داء السكري من النمط الأول.

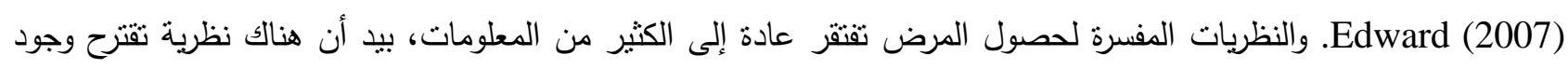

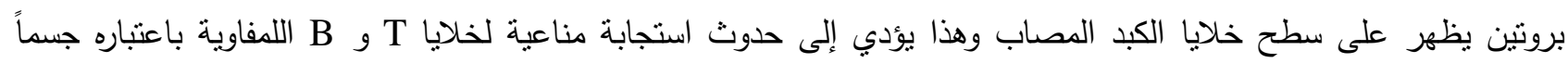


غريباً وبالتالي إنتاج الأجسام المضادة الذانية التي تصيب خلايا الكبد محثثة حالة التهابية تؤدي إلى تحطيم خلايا وأنسجة

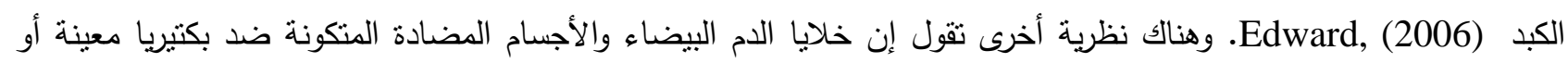

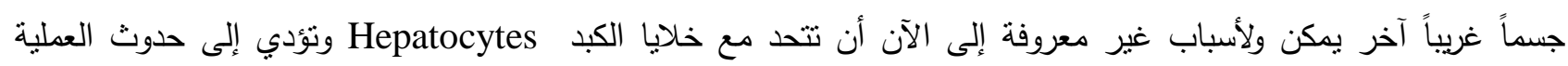

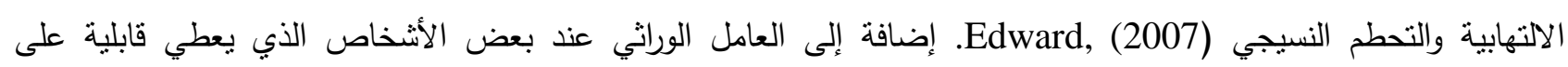
الإصابات المناعية الذاتية عند الثخص ضمن العائلة الواحدة (2007) (Edward, إن مرض التهاب الكبد المناعي الذاتي AIH يكون شائعا عادة عند النساء أكثر من الرجال كما مر انفا وبنسب مختلفة، وهذا يدل على أن الاختلافات الهرمونية قد يكون لها علاقة مباشرة في إحداث المرض، وتبلغ خطورة المرض حدّها عند النساء عنداء

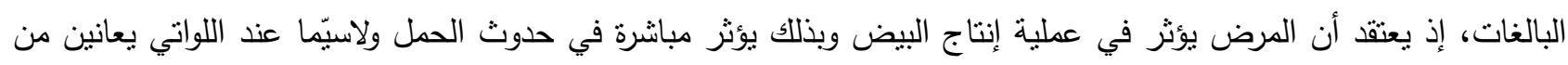

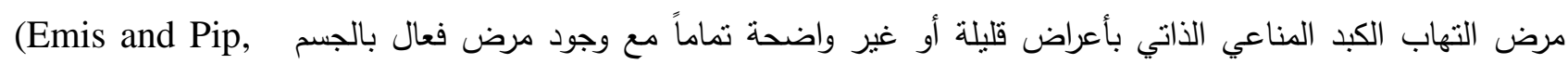
.2006)

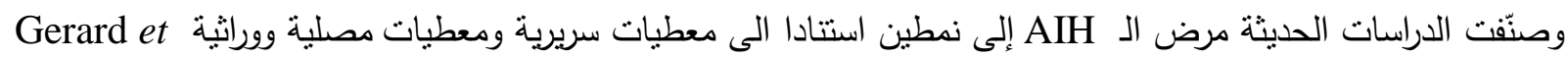
(2007) , al. النمط الأول: التهاب الكبد المناعي التقليدي: ويشكل 70 - 80\% من الحالات، ويكون أكثر شيوعاً في أميركا ويتميز بوجود عدة أضداد مناعية ذاتية، خاصة أضداد النوى ANA وأضداد العضلات الملساء و et al., (2015) ASMA

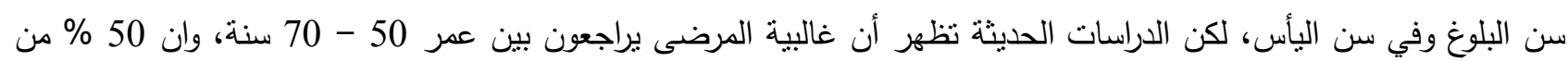

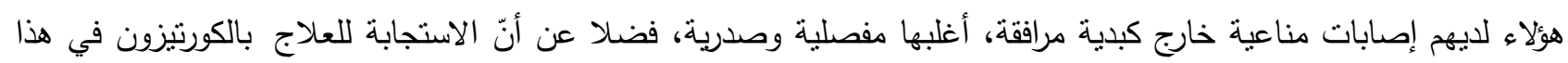

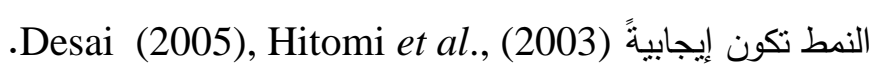
النمط الثاني: نادر الحدوث 3-4 \%، وقد اكتثف عام 1980 وهو يصيب الفتيات خصوصاً بين أعمار 2-14 سنة ويمكن أن يصيب الكبار أيضاً، ويتميز بوجود أضداد الميكروزوم للكبد والكلية Michael et al., (2015) Anti-LKM هو يبدأ بعمر وفر

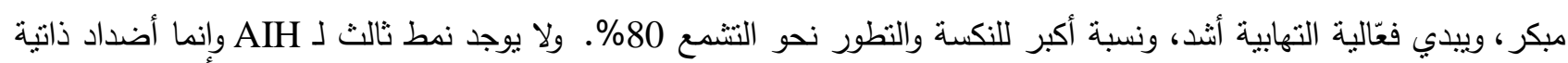
مختلفة يمكن أن تظهر في أحد النوعين الأساسيين للمرض. وهناك 20-30\% من الحالات تكون فيها الأضداد السابقة سلبية،

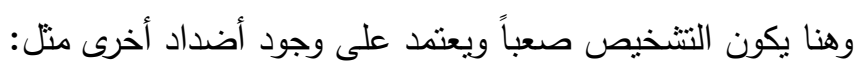
PANCA : Perinuclear staining antineutrophil cytoplasmic antibodies

نوى الكريات البيض المثبتة بالكحول (2007) , Gerard et al., وهناك أضداد أخرى أكثر نوعية وهي:

Anti SLA: Anti soluble liver antigens antibodies

Anti LP: Anti liver pancreas protein antibodies

وأثنتت الدراسات الحديثة أن Anti-LP و Anti-SLA هي نفس الأضداد وهي نوعية تثاهد بشكل خاص في النمط الأول

.Jason et al., (2007), Lok-Beng et al., (2006)

وكذلك الحال في Anti- LC1 : Anti- liver cytosolic antibodies وهي عبارة عن أضداد بروتين العصارة الخلوية وغالباً

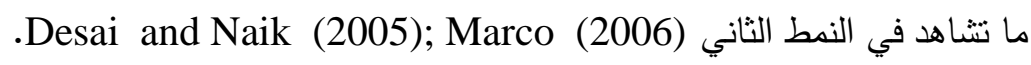
إن الأعراض المرضية لالتهاب الكبد المناعي الذاتي AIH في كثير من الحالات تتطور في غضون أسابيع إلى عدة أثهر،

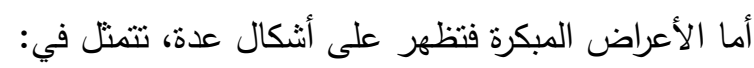

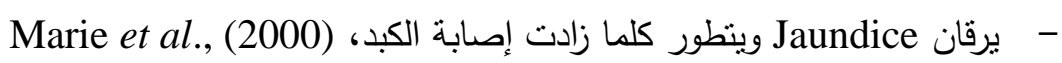




$$
\text { محمود عبد الجبار حسين وآخرون }
$$

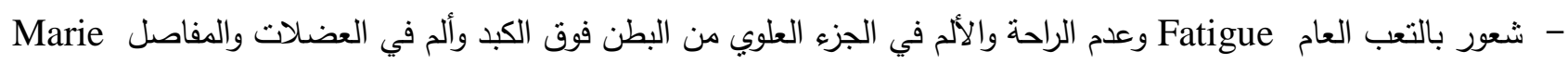
. et al., (2000)

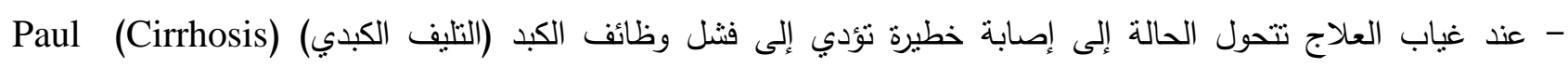
· gueguen et al., (2006); Pia Lebiedz et al., (2008) - - وفي بعض الحالات تتطور الأعراض بسرعة خلال أيام قليلة (في حالته الثديدة) وتبدأ بالحمى وألم في البطن ويرقان

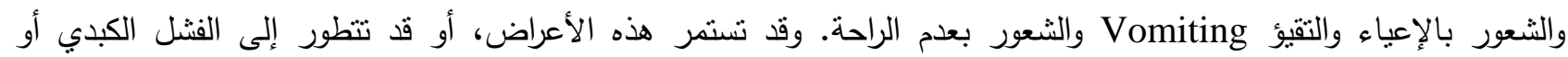

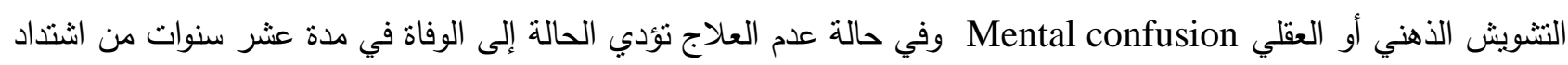

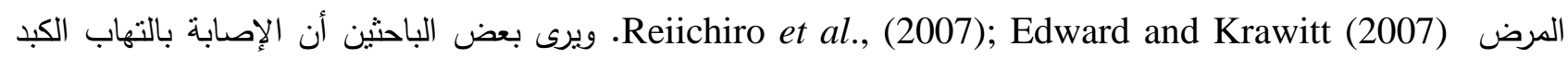

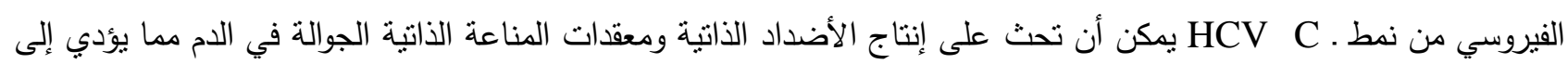
الإصابة بالمرض المناعي الذاتي (Johnson and Gretch, 1993; Weisendaul et al., 1995).

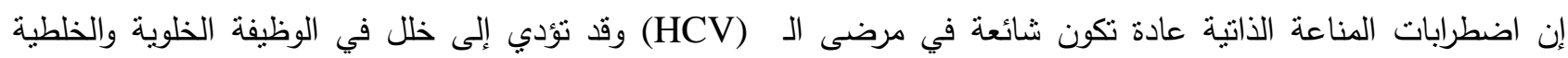

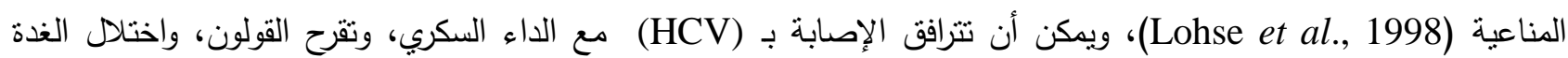

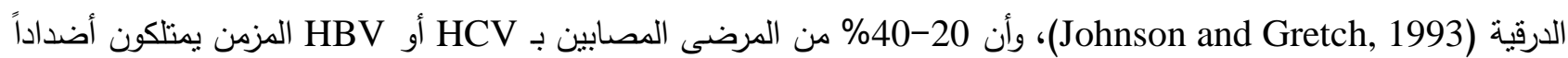
ذاتية بقيحٍ منخفضة 1/20-1/40.

\section{المواد وطرائق العمل}

المواد: تم استخدام الأجهزة والمواد الآتية لغرض إجراء البحث: · جهاز آلي لتحليل الدم CBC نوع Horiba Abx Diagnostics لتحديد مستوى الخضاب في الدم وتعداد خلايا صفيحات الدم. . جهاز طرد مركزي لترسيب كريات الدم من نوع Hettich وبسرعة 3000 دورة بالدقيقة.

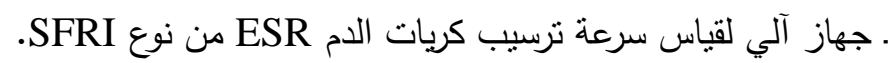
. جهاز قياس سرعة ترسيب كريات الدم يدوي(عادي). ـ أنابيب مختلفة حاوية على مانع تخثر وتتسع إلى 10 مللتر من الدم، وأنابيب خاصة لقياس سرعة ترسيب تربيب كريات الدم الحمراء. . ماصة أوتوماتيكية. زجاجيات مختلفة، وحامل أنابيب. . سرنجات لسحب الدم (5,10 مللتر ). طرائق العمل:

تم جمع 167 عينة دم من المرضى الراقدين في مستتشفيات الجامعة وزاهي ازرق وممن لديهم أعراض مرضية مختلفة وتراوحت أعمار المرضى من 9 -75 سنة ومن كلا الجنسين ذكور وإناث، وتم تخصيص استمارة معلومات لكل مريض أدخلت فيها معلومات عامة عن المريض تضمنت: العمر ، الجنس، المهنة، محل السكن، المستوى المعاثي، المستوى التعليمي، إضافة ونة إلى تأريخ العائلة المرضي، ووجود أمراض أخرى مرافقة، والتشخيص الأولي للمرض، وتقرير تصوير البطن (الايكو)، والعلاج

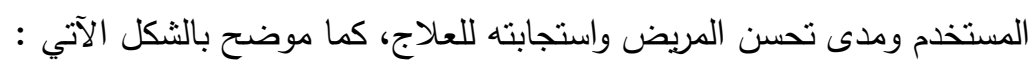



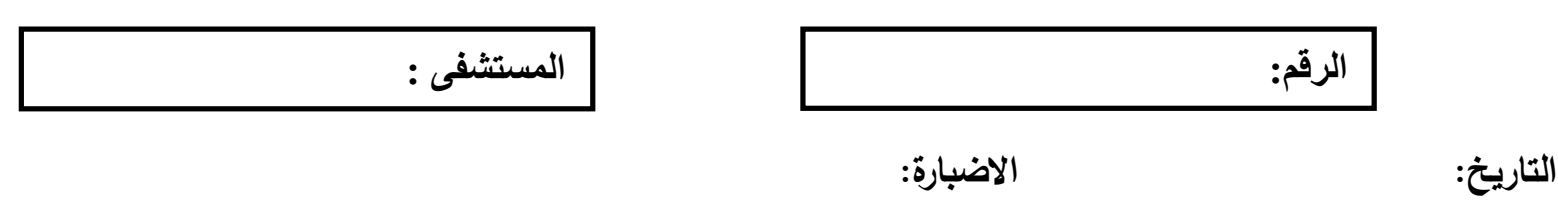

معلومات عامة

$$
\begin{aligned}
& \text { الاسم : } \\
& \text { الجنس : } \\
& \text { العمر : } \\
& \text { المستوى المعاشي (الاخل) : } \\
& \text { المستوى الثقافي (التعليم) : } \\
& \text { المهنة : } \\
& \text { محل السكن : } \\
& \text { معلومات صحية } \\
& \text { تاريخ العائلة (وجود إصابات سابقة في العائلة) : } \\
& \text { وجود أمراض أخرى : } \\
& \text { ممارسة الرياضة اليومية : }
\end{aligned}
$$

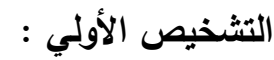

$$
\begin{aligned}
& \text { الأعراض المرضية : } \\
& \text { تدخين : } \\
& \text { كحول : } \\
& \text { العلاج المستخدم سابقا (إن وجد) : } \\
& \text { الحالة قبل استخدام العلاج : } \\
& \text { الحالة بعد استخدام العلاج : } \\
& \text { الملاحظات(تقرير الايكو): }
\end{aligned}
$$

الثكل 1: استمارة المعلومات

نم العمل في مخبر أبحاث الطفيليات في كلية العلوم جامعة حلب وكذلك في المخبر المركزي في مستشفى زاهي ازرق.

$$
\text { 1-اختبار سرعة ترسيب كريات الام الحمراء: ESR }
$$

تم استخدام جهاز آلي حديث لقياس سرعة ترسيب كريات الدم الحمراء باستخدام أنابيب خاصة للجهاز حاوية على مانع

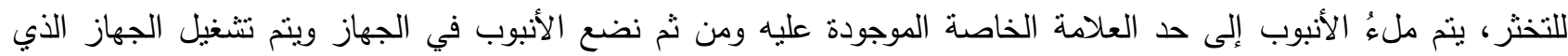




$$
\text { محمود عبد الجبار حسين وآخرون }
$$

يعطي النتيجة خلال نصف ساعة لسرعة ترسيب كريات الدم لمدة ساعة واحدة فقط 1h. وخلال ساعة واحدة بعطي الجهاز نتيجة سرعة الترسيب لساعتين 2h. وكما استعملت الطريقة القديمة في تحديد سرعة ترسيب كريات الدم الحمراء باستخدام ماصات خاصة ددرجة وحامل لها ويتم ملءُ الماصة أوتوماتيكياً ومن ثم نضعها على الحامل ونستخدم ساعة نوقيت للحصول على القراءة خلال ساعة واحدة .

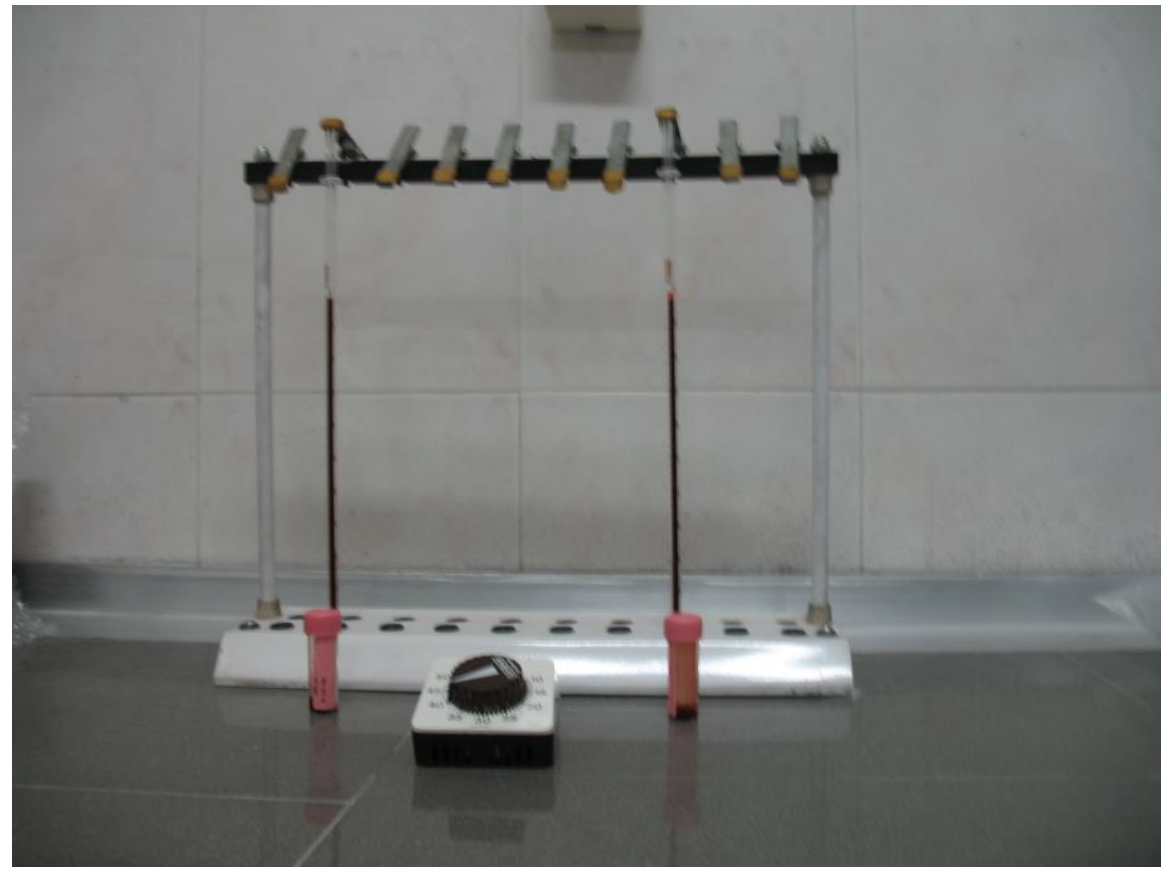

الشكل 2: جهاز قياس سرعة ترسيب كريات الام الحمراء (الطريقة القديمة)

CBC : قياس مكونات الام باستخدام جهاز

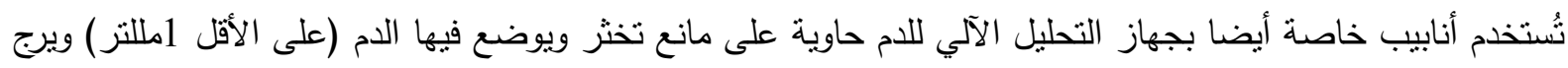

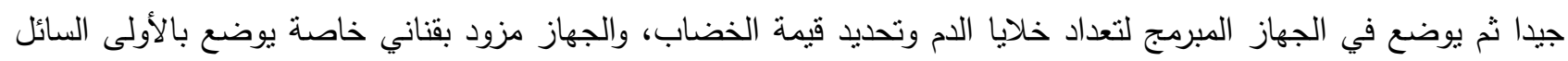

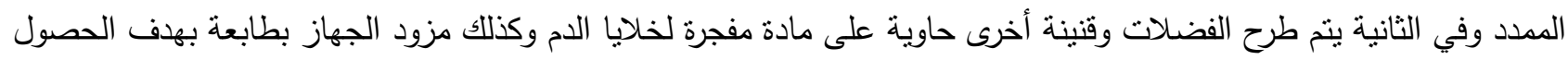
على النتائج بشكل نظامي. 3- قياس زمن البروثرومبين: تم قياس زمن البروثرومبين بالطريقة القديمة، حيث يتم إضافة 100 مبكروليتز من مادة الثرمبوبلاستين (المستخرجة من

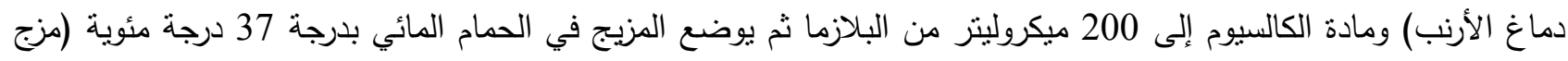

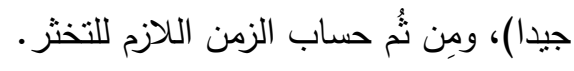

\section{النتائج وإلمناقشة}

أجريت التحليلات الدموية للمرضى قيد الدراسة وشملت هذه التحليلات سرعة ترسيب كريات الدم الحمراء ESR، والتعداد

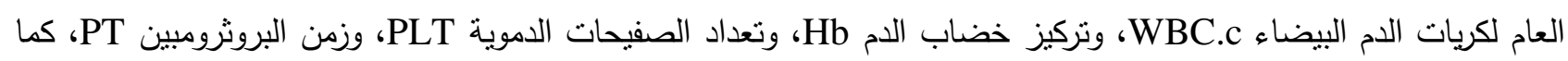
تم تحديد مدى العلاقة بين مرضى التهاب الكبد المناعي الذاتي والتهاب الكبد الفيروسي C. وباقي المرضى لعنى من ناحية التحاليل

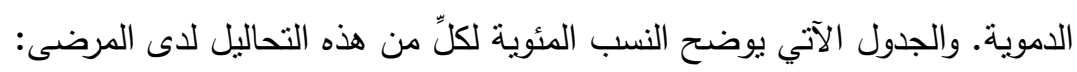


الجدول 1: النسب المئوية للتحاليل الدموية للمرضى

\begin{tabular}{|c|c|c|c|c|c|c|c|c|c|c|}
\hline \multicolumn{3}{|c|}{$\begin{array}{c}\text { العينات السلبية } \\
\text { AIH\&HCV }\end{array}$} & \multicolumn{3}{|c|}{ HCV } & \multicolumn{3}{|c|}{ AIH } & \multirow{2}{*}{ القيم الطبيعية } & \multirow{2}{*}{ نوع التحليل } \\
\hline$\%$ & الطينير & العفينات & $\%$ & الطينية & العفحوصة & $\%$ & الطيير & المفحوصة & & \\
\hline 62.1 & 34 & 54 & 70.1 & 22 & 31 & 72.22 & 26 & 36 & $\begin{array}{c}15-0 \\
\mathrm{~mm} / \mathrm{h}\end{array}$ & $\uparrow$ ESR \\
\hline 6.75 & 5 & 74 & 28.13 & 9 & 32 & 28.57 & 12 & 42 & $\begin{array}{c}9.8-3.2 \\
\mathrm{~mm}\end{array}$ & $\begin{array}{c}\text { W.B.C.C } \\
\downarrow \\
\end{array}$ \\
\hline 71.42 & 55 & 77 & 87.9 & 29 & 33 & 84.1 & 37 & 44 & $\begin{array}{l}17.7-13.6 \\
\mathrm{~g} / 100 \mathrm{~mm}\end{array}$ & $\mathbf{H} \mathbf{b} \downarrow$ \\
\hline 15.28 & 11 & 72 & 41.94 & 13 & 31 & 17.07 & 7 & 41 & $\begin{array}{c}400-130 \\
1000 \times\end{array}$ & $\overline{\text { PLT } \downarrow}$ \\
\hline 92.68 & 38 & 41 & 85.71 & 24 & 28 & 84.85 & 28 & 33 & $\begin{array}{c}12-10 \\
\text { Sec }\end{array}$ & $\begin{array}{l}\text { P.T } \uparrow \\
\end{array}$ \\
\hline
\end{tabular}

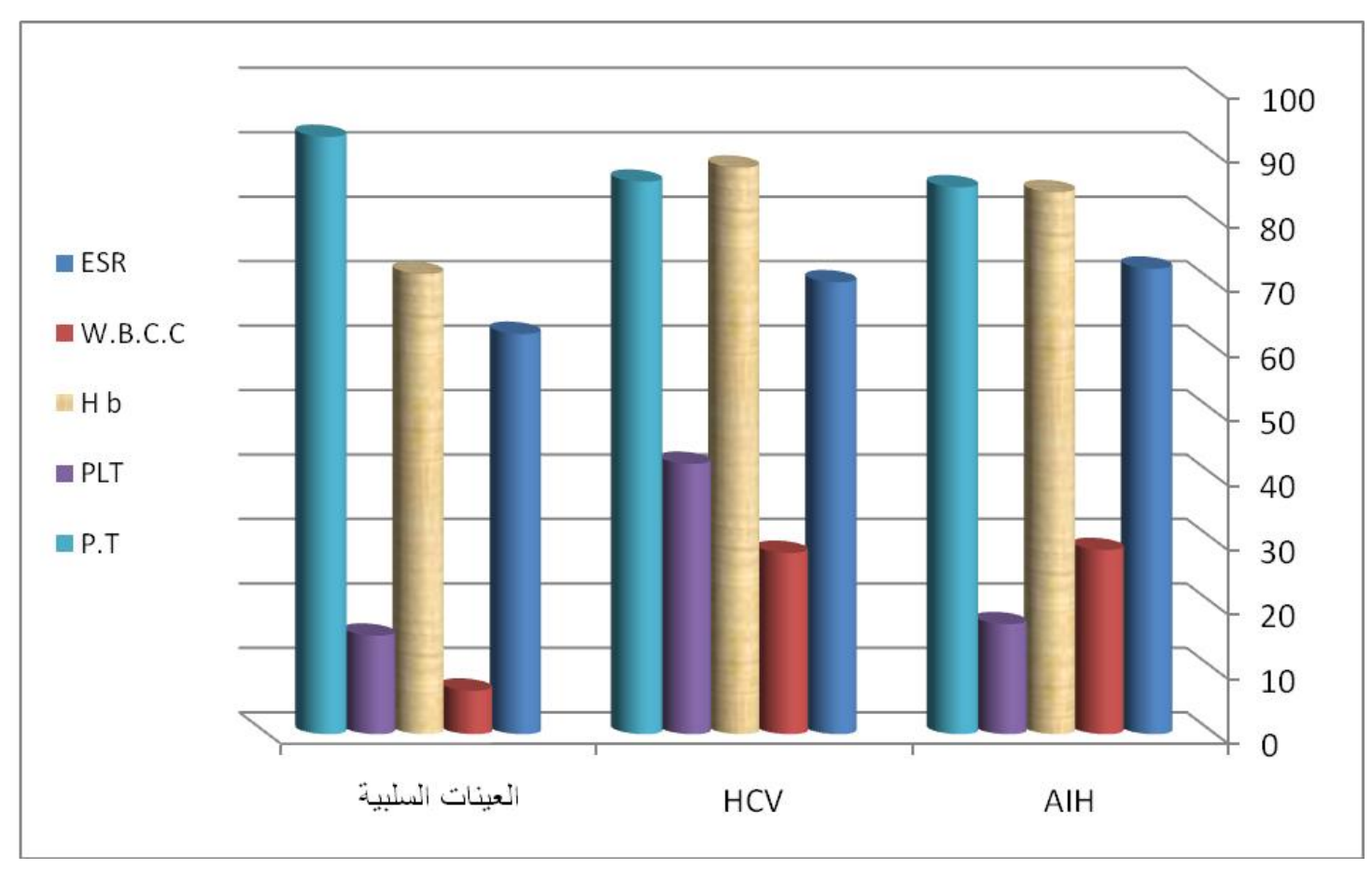

الثكل 3: النسب المئوية للتحاليل الاموية للمرضى

إن التغيرات في التحاليل الدموية تكون في العادة منتابهة في حالات التهابات الكبد المختلفة، حيث نلاحظ دائما ارتفاع في

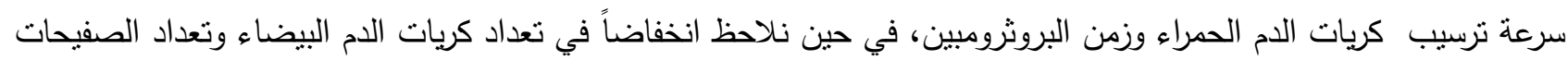
الدموية وكذلك انخفاض في مستوى خضاب الدم، وذلك بسبب الضرر الحاصل في الخلايا الكبدية في أثثاء الإصابة، وتنتاسب 
هذه القيم مع شدة الحالة المرضية والأعراض التي يعاني منها المريض إضافة إلى الاختلافات الطفيفة في قيم هذه التحاليل حسب نوع التهاب الكبد، إذ نلاحظ من (الجدول 1) إن نسبة القيم غير الطبيعية في سرعة نرسيب كريات الدم الحمراء كانت منقاربة في

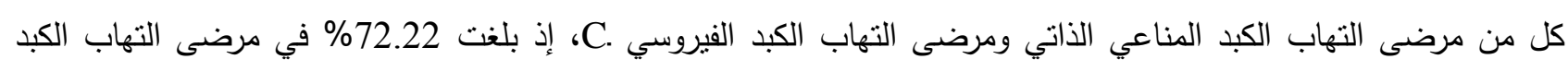

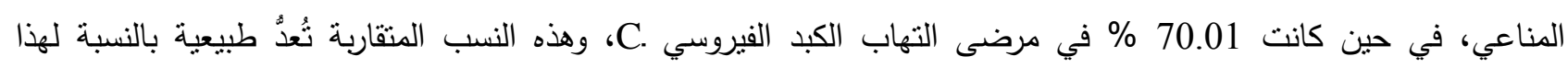

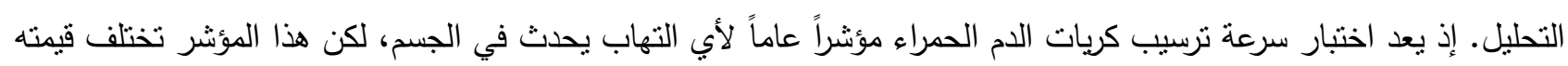

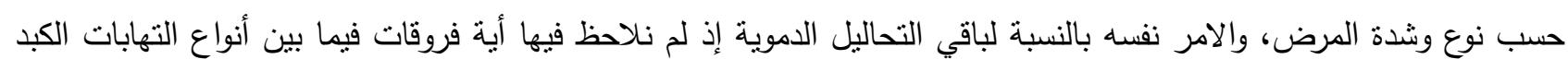

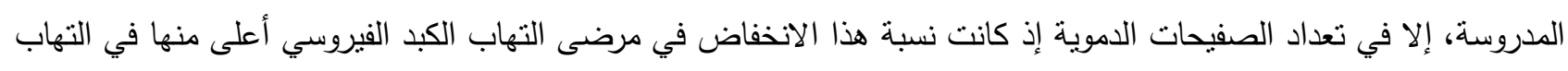

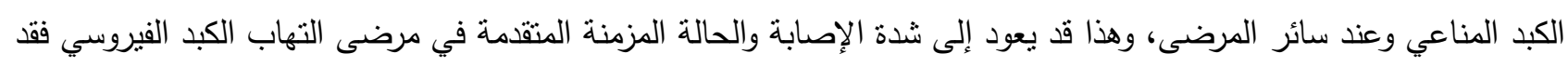

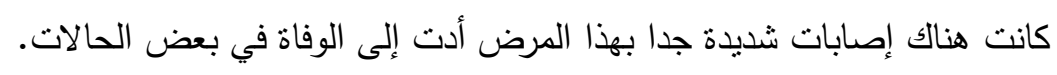

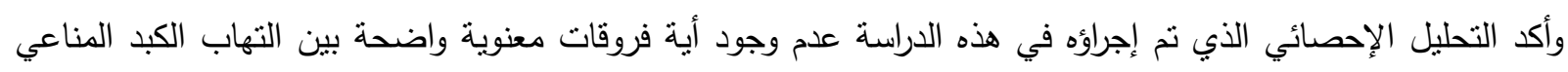

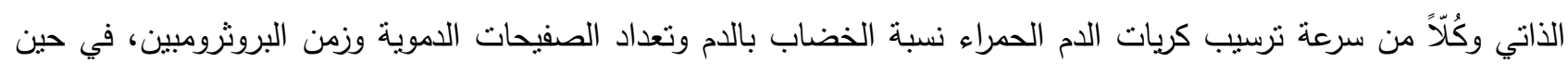

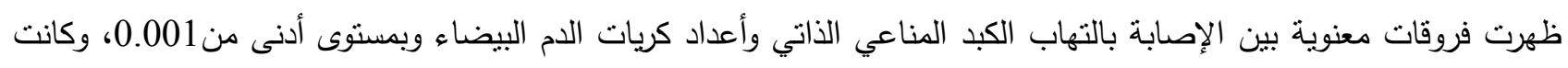

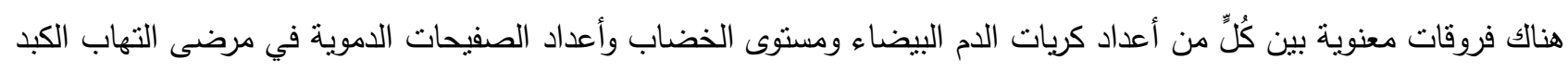

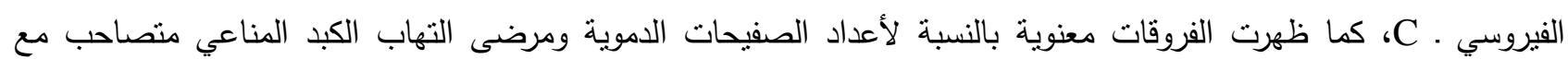
التهاب الكبد الفيروسي، كما موضح بـ (الجدول 2).

الجدول 2: الفروقات المعنوية بين الاختبارات الدموية وأمراض AIH\&HCV

\begin{tabular}{|r|r|r|r|}
\hline HCV & AIH & AIH \& HCV & \\
\hline 0.227 & 0.181 & 0.455 & ESR \\
\hline$* 0.0014$ & $*<0.001$ & 0.483 & WBC \\
\cline { 2 - 4 }$* 0.0314$ & 0.058 & 0.235 & Hb \\
\cline { 2 - 4 }$* 0.0017$ & 0.401 & $* 0.0098$ & PLT \\
\hline 0.202 & 0.168 & 0.462 & PT \\
\hline
\end{tabular}

ومما هو جدير بالذكر أنّ دراسة جرت في اليابان على 47 امرأة راجعنَ مستتفى Chiba الجامعي عام 1996 بسبب فشل وظيفة الكبد، إذ ظهر زمن البروثرومبين بمنوسط 12.9 ثانية، وفي عام 1999 وأجريت نفس الدراسة على 39 من النساء دراء يعانين

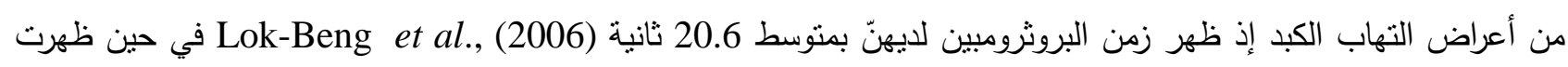
قيمة البروثرومبين في هذه الدراسة بمتوسط 22.8 ثانية في نتيجة مقاربة للاراسة التي أجريت عام 1999 في اليابان.

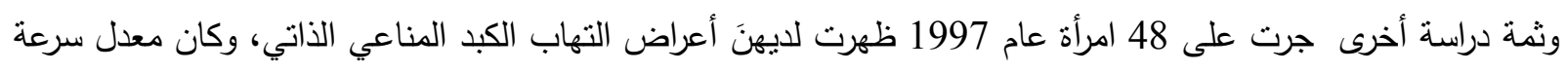
ترسيب كريات الدم الحمراء 60 h / mm ESR، واظهر زرع الدم نتائج سلبية للبكتيريا والفيروسات مع وجود أضداد ذاتية .Tatsuo Kanda et al., (2006) كريات الدم الحمراء في المرضى 67 / mm إن ظهور التهاب الكبد المناعي الذاتي قد يتزامن مع الإصابة بالتهاب الكبد الفيروسي C، و فلفي دراسة أجريت على 34

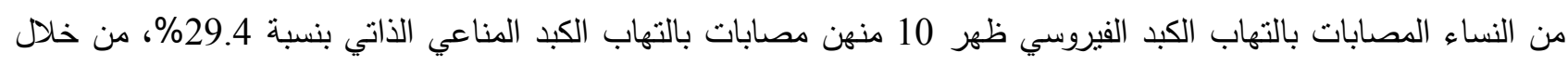


تحديد الأضداد الذاتية للنواة ANA وبعيارية 20/1>، مع سلبية لـ AMA، وظهرت القيم المخبرية للتحاليل الدموية للمرضى بارتفاع زمن البروثزومبين بنسبة 81.2\%، ومتوسط الخضاب بلغ 11.3 / gl g ومتوسط تعداد كريات الدم البيضاء بلغ

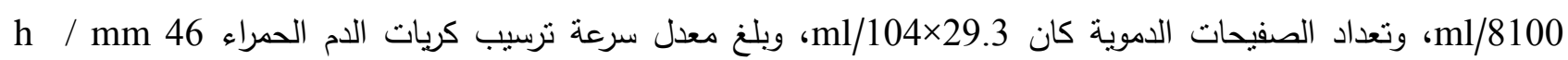
وهذه النتائج متفاوتة بين التطابق والاختلاف مع النتائج التي حصلنا عليها في هذا البحث، إذ نلحظ معات تطابق نسبة ارتفاع زمن البروثرومبين، في حين اختلفت قيمة الخضاب إذ بلغ منوسطها g/100mm 9.6 في المرضى قيد

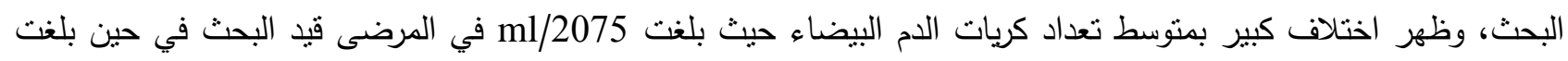

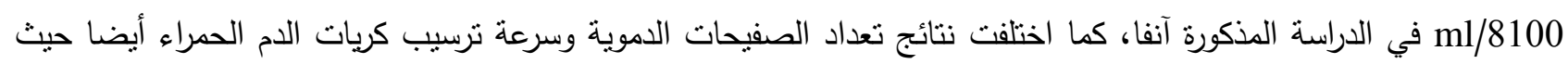

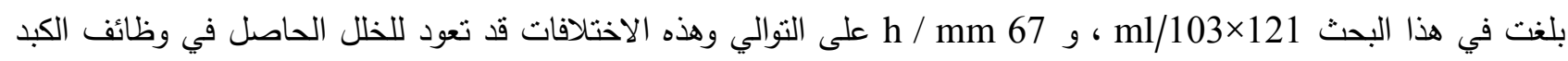
نتيجة الاصابة بالمرض. وخلال الفترة ما بين 2000 لغاية 2004 دُرست 48 حالة من الـ AIH شخصت في اليابان، رُصدت وكانت جميع الحالات

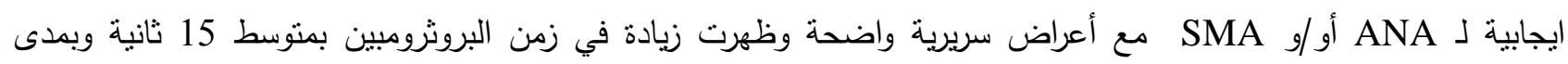

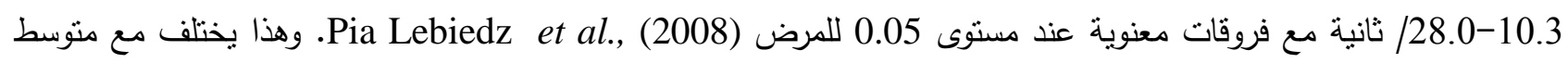
زمن البروثرومبين الذي نم الحصول عليه في هذا البحث حيث بلغ 22.8/ ثانية، ويمكن الاعتماد على النتائج التي حصلنا عليها بثكل أكثر دقة وشمولاً حيث تم الاعتماد على عدد كبير من العينات بلغ 167 عينة، في حين اعتمد البحث الدذكور على 48 عينة فقط.

\section{المصادر}

Adam, B. (2006). Autoimmune hepatitis. Medical Center at Chicago. Health library.

Albert, J.; Czaja, M.D.; Herschel, A.; Carpenter, M.D. (2006). Thiopurine methyltransferase deficiency and azathioprine hepatitis. Digestive Disease and Sci., 51(5), 968-975.

Aizawa, Y.; Hokari, A. (2017). Autoimmune hepatitis: current challenges and feature prospects. Clin. Exp. Gastroenterol (Review). 10, 9-18. Doi: 10.2147.

Desai, H.; Naik, A. (2005). Acute viral E hepatitis with chronic liver disease (Autoimmune hepatitis). Indian J. Medical Sci.

Edward, L.; Krawitt, M.D. (2007). Pathogenesis of autoimmune hepatitis. Licensed to First Last. www.uptodate.com.

Edward, K. (2006). Autoimmune hepatitis. The new England J. Medicine. 354(1),1, 54, 15.

Emis, P. (2006). Autoimmune hepatitis. British liver trust. www.britishlivertrust.org.uk.

Gerard, O.; Bruce, McCarty; Haesung, B.; Andrew, S.J. (2007). Autoimmune hepatitis following infliximab therapy for ankylosing spondylitis. Medical J. Australia. Pyrmont. 187(9), 524, 3.

Hitomi, S.; Yasuji, A.; Akihito, T.; Yoshiyuki, S.; Masahiro, K.; Satoshi, S.; Fumitaka, S.; Norio, A.; Takashi, S.; Kenji, I.; Hiromitsu, K. (2003). Type C-chronic hepatitis patients who had autoimmune phenomenon and developed jaundice during interferon therapy. $J$. Gastroenterol, (38), 493-500.

Jason, J.L.; Julia, C.I.; Carl, L.B. (2007). Methylphenidate-Induced autoimmune hepatitis. Dig. Dis. Sci., 52, 594-597.

Johnson, R.; Gretch (1993). Membranoproliferative glomerulonephritis associated with hepatitis C virus infection. N. Engl. J. Med. 328, 465-70.

Lohse, A.; Gerken, G.; Meyerzum, B. (1998).Autoimmune hepatitis and hepatitis C virus infection. Curr. Stud. Hematol. Blood Transfus., 62, 152-60. 


$$
\text { محمود عبد الجبار حسين وآخرون }
$$

Lok-Beng, K.; Ching-Yih, L.; Sun-Lung, T.; Chuan Lee.; Ching-Nan, L.; Ming-Juen, S. (2006). Type 1 autoimmune hepatitis in Taiwan: Diagnosis using the revised criteria of the International autoimmune hepatitis group. Dig. Dis. Sci., 51, 1978-1984.

Manns, M.P.; Strassburg, C.P. (2001). Update on the clinical presentation and treatment of AIH. Clinical Challenges. Gastroenterology. 120, 1502-1517.

Marco, C. (2006). Toll-like receptors and IFN-[alpha]:partners in autoimmunity. J. Clin. Invest., 116(9), Pro Quest Medical Library. 2319.

Marie, I.; Levesque, H.; Courtois, H.; Francois, A.; Riachi, G. (2000). Polymyositis, cranial neuropathy, autoimmune hepatitis, and hepatitis C. Annals. Rheumatic. Diseases. London. 59(10), 839, 2.

Michael, P.; Manns, A.W.; Lohse, Di Vergeni (2015). Autoimmune hepatitis. J. Hepatology, 62, s100-s111.

Paul, G.; Georgios, D.; Jean-Baptiste, N.; Kalliopi, Z.; Chaim, P.; Pierre, Y.; Yves, R. (2006). Double reactivity against actin and $\alpha$-actinin defines a severe from of autoimmune hepatitis type-1. J. Clin. limmunol., 26(6), 10.1007/s10875-006-9045-z.

Pia, L.; Christian, A.; Wolfram, Do.; Hartmut, H.J.S. (2008). Interferon (IFN) for malignant melanoma unmasking an autoimmune hepatitis. Europ. J. Med., doi: 10.1016/j.ejim.07010.

Reiichiro, K.; Hiroki, S.; Mitsuhiko, A.; Akio, T.; Kazuo, T.; Teruko, H.; Tatsuya, I.; Ryoko, K.; Ken, T.; Masayoshi, K.; Ryukichi, K.; Michio, S. (2007). Succeful Treatment with corticosteroid and lamivudine for autoimmune hepatitis in a patient with asymptomatic HBV infection. Dig. Dis. Sci., 52, 908-913.

Tatsuo, K.M.D.; Osamu, Y.M.D.; Yuichi, H.M.D.; Fumio, I.M.D.; Keiichi, N.M.D.; Hiromitsu S. M.D. (2006). Occurrence of autoimmune hepatitis during the course of primary biliary cirrhosis: Report of two cases. Dig. Dis. Sci., 51(1), 45-46.

Washington, K.M. (2007). Autoimmune liver disease: overlap and outliers. Modern Pathology, 20, S15-S30. dio: 10.1038.

Weisendaul, D.; Imam, T.; Holyst, M.; King, P.; McMurray, R.(1995). Polymyositis, Pulmonary fibrosis and hepatitis C. Arthritis Rheum. 38, 437-9. 